\title{
Recent advances in clinical application of optical coherence tomography of human skin
}

This article was published in the following Dove Press journal:

Clinical, Cosmetic and Investigational Dermatology

7 July 2015

Number of times this article has been viewed

\section{Thilo Gambichler \\ Azem Pljakic \\ Lutz Schmitz}

Department of Dermatology, RuhrUniversity Bochum, Bochum, Germany
Correspondence: Thilo Gambichler Department of Dermatology, RuhrUniversity Bochum, Gudrunstr 56,

D-4479I Bochum, Germany

Tel +492345093458

$\mathrm{Fax}+492345093445$

Email t.gambichler@klinikum-bochum.de
Abstract: Optical coherence tomography (OCT) is an emerging noninvasive imaging method that uses infrared light and interferometric techniques. The method has become increasingly popular in skin research as well as daily dermatology practice. In the present brief review, we focused on recent (2009-2014) OCT studies on the human skin, which included a reasonable sample size and statistics. Twenty-five papers were selected and briefly described OCT of epidermal thickness, skin appendages, wound healing, extracellular matrix and skin fibrosis, vascular malformations, and skin tumors such as basal cell carcinoma, actinic keratoses, and malignant melanoma.

Keywords: optical coherence tomography, dermatology, skin imaging, interferometry, histology

\section{Introduction}

Optical coherence tomography (OCT) - introduced in 1997 in the dermatology discipline - is an emerging noninvasive imaging method that uses infrared light and interferometric techniques. OCT has become a widely used technique in skin diagnostics, providing optical cross- as well as en-face sections through the skin with high resolution. OCT B-scans are comparable to the standard of histology sections obtained by invasive skin biopsies. Using OCT, cutaneous micromorphology and pathology can be investigated in situ and in real-time, without the removal of tissues, thus enabling the same tissue location to be monitored over time. Apart from skin cancer, for example, therapeutic effects, physical and chemical hazards, and surgical interventions have also been studied, both during initial treatment and in long-term follow-up. Innovative OCT systems with significant improvements with regard to the speed of image acquisition, resolution, and scan field have recently been developed, increasing the utility of this imaging technique for noninvasive studies of the human skin. ${ }^{1-3}$

We aimed to review recent (January 2009-October 2014) advances in the clinical application of OCT of the human skin, focusing on studies that included a reasonable sample size and statistical analysis. Hence, searches were made in the electronic database of PubMed using the search terms: (optical coherence tomography) and (skin). Studies were included in this review, if original data were reported, if human subjects were assessed by means of OCT (sample size of at least 20), and if statistical analyses were reported. Based on the aforementioned criteria, we selected 25 papers, ${ }^{4-28}$ which are briefly summarized and discussed in this review (Table 1). 
Table I Selected papers ordered by the OCT system used

\begin{tabular}{|c|c|c|c|c|}
\hline OCT System & Specifications & Author & Application & $\begin{array}{l}\text { Patients } \\
\text { (n) }\end{array}$ \\
\hline \multirow{8}{*}{$\begin{array}{l}\text { VivoSight; Michelson } \\
\text { Diagnostics, Kent, UK } \\
\text { SS-OCT }\end{array}$} & \multirow{8}{*}{$\begin{array}{l}\text { Optical resolution (in tissue): } \\
<7.5 \mu \mathrm{m} \text { lateral, }<5 \mu \mathrm{m} \text { axial, } \\
\text { penetration depth up to } 2 \mathrm{~mm}\end{array}$} & \multirow[t]{2}{*}{ Abignano et $\mathrm{al}^{4}$} & Skin fibrosis (patients with & \multirow[t]{2}{*}{44} \\
\hline & & & scleroderma vs healthy controls) & \\
\hline & & Aydin et $\mathrm{al}^{6}$ & Skin appendages, nail (psoriasis) & $\begin{array}{l}\text { I8 (180 nail } \\
\text { samples) }\end{array}$ \\
\hline & & Coleman et $\mathrm{al}^{7}$ & NMSC (histological correlates) & 87 \\
\hline & & \multirow[t]{2}{*}{ Cunha et $\mathrm{al}^{8}$} & NMSC (comparison of ex vivo & \multirow[t]{2}{*}{75} \\
\hline & & & $\begin{array}{l}\text { OCT with frozen-section histology } \\
\text { for identifying } B C C \text { ) }\end{array}$ & \\
\hline & & Greaves et $\mathrm{al}^{14}$ & Wound healing & 50 \\
\hline & & Wang et $\mathrm{al}^{25}$ & $\begin{array}{l}\text { NMSC (define excision margins } \\
\text { before MMS) }\end{array}$ & 52 \\
\hline \multirow{7}{*}{$\begin{array}{l}\text { SkinDex300; ISIS Optronics } \\
\text { GmbH, Manheim, Germany }\end{array}$} & \multirow{7}{*}{$\begin{array}{l}\text { Average refractive index of the } \\
\text { sample medium } n_{\text {med }}=n_{\text {obj }}=I .43 \text { : } \\
\text { depth resolution } \hat{=} A-F W M_{\text {Int }} \\
=7.4 \mu \mathrm{m} \text {; numerical aperture of } \\
\text { the focusing lens is } \mathrm{NA}=0.19 \text { : } \\
\text { diffraction-limited lateral resolution } \\
\hat{=} \text { A-FWHM } \\
\text { center wavelength }\end{array}$} & \multirow{5}{*}{$\begin{array}{l}\text { Garcia Bartels } \\
\text { et } \mathrm{al}^{13} \\
\text { Josse et al } \\
\text { Lindner et } \mathrm{al}^{16}\end{array}$} & \multirow[t]{2}{*}{ Skin appendages, hair (AA) } & \multirow{2}{*}{$\begin{array}{l}9 \text { (450 hair } \\
\text { samples) }\end{array}$} \\
\hline & & & & \\
\hline & & & ET, healthy skin & 29 \\
\hline & & & $\begin{array}{l}\text { Skin appendages, hair shaft } \\
\text { alterations after chemotherapy }\end{array}$ & 34 \\
\hline & & & and tamoxifen therapy & \\
\hline & & Tsugita et $\mathrm{al}^{24}$ & ET, healthy skin & 116 \\
\hline & & Scola et $\mathrm{al}^{28}$ & $\begin{array}{l}\text { NMSC (PDT vs } \mathrm{CO}_{2} \text { laser in } \\
\text { AK treatment) }\end{array}$ & 20 \\
\hline \multirow{4}{*}{$\begin{array}{l}\text { Skintell; Agfa Healthcare, } \\
\text { Mortsel, Belgium }\end{array}$} & \multirow{4}{*}{$\begin{array}{l}\text { Vertical and lateral resolution } \\
3 \mu \mathrm{m} \text { at all depths of the skin } \\
\text { sample, penetration depth of } \\
570 \mu \mathrm{m}\end{array}$} & Gambichler et al ${ }^{9}$ & NMSC (characterization of BCC) & 25 \\
\hline & & Gambichler et al $^{10}$ & Melanocytic skin lesions & 48 \\
\hline & & Gambichler et al'" & $\begin{array}{l}\text { Differentiation between benign and } \\
\text { malignant melanocytic skin lesions }\end{array}$ & 93 \\
\hline & & Gambichler et al ${ }^{12}$ & $\begin{array}{l}\text { ET, cutaneous disorders } \\
\text { (psoriasis and AK) }\end{array}$ & 24 \\
\hline \multirow{4}{*}{$\begin{array}{l}\text { OCT developed at Risø } \\
\text { National Laboratory, } \\
\text { Denmark }\end{array}$} & \multirow{2}{*}{$\begin{array}{l}\text { Vertical resolution } 8 \mu \mathrm{m} \text {, lateral } \\
\text { resolution } 24 \mu \mathrm{m}, 1,318 \mathrm{~nm}\end{array}$} & \multirow[t]{2}{*}{ Mogensen et $\mathrm{al}^{19}$} & NMSC (benign vs malignant & \multirow{2}{*}{$\begin{array}{l}104(176 \\
\text { lesions) }\end{array}$} \\
\hline & & & lesions) & \\
\hline & \multirow[t]{2}{*}{ center wavelength } & Mogensen et $\mathrm{al}^{20}$ & $\begin{array}{l}\text { NMSC (comparing in vivo thickness } \\
\text { measurement of } B C C \text { and } A K \text { with } \\
\text { OCT and } 20 \mathrm{MHz} \text { HFUS }\end{array}$ & 34 lesions \\
\hline & & Morsy et $\mathrm{al}^{21}$ & ET, cutaneous disorders (psoriasis) & 23 \\
\hline DermaRadar 830; Technische & \multirow[t]{3}{*}{ Resolution data NA } & \multirow[t]{3}{*}{ Aschoff et $\mathrm{al}^{5}$} & ET, cutaneous disorders (atopic & \multirow[t]{3}{*}{20} \\
\hline Universität, Dresden, & & & dermatitis and treatment with & \\
\hline Germany FD-OCT & & & HCT I\% cream vs PIM I\% cream) & \\
\hline OCSI300SS; Thorlabs ${ }^{\circledR}$, & I,325 nm center wavelength, & Hinz et al $^{15}$ & Melanocytic skin lesions (tumor & 26 \\
\hline \multirow[t]{3}{*}{ Dachau, Germany } & $25 \mu \mathrm{m}$ (lateral) $\times 12 \mu \mathrm{m}$ (axial) & & thickness measured by OCT vs & \\
\hline & resolution (air), penetration depth & & HFUS) & \\
\hline & up to $3 \mathrm{~mm}$ & & & \\
\hline Thorlabs $^{\circledR}$, Newton, NJ, USA & $\begin{array}{l}930 \mathrm{~nm} \text { center wavelength, lateral } \\
\text { resolution } 8 \mu \mathrm{m}\end{array}$ & Meyer et $\mathrm{al}^{18}$ & $\begin{array}{l}\text { Melanocytic skin lesions (tumor } \\
\text { thickness measured by OCT vs }\end{array}$ & 138 \\
\hline & & & HFUS vs histology) & \\
\hline PS-OCT & $\begin{array}{l}\text { Depth resolution in air: } 10.2 \mu \mathrm{m} \text {, } \\
\text { further specifications NA }\end{array}$ & Sakai et $\mathrm{al}^{22}$ & $\begin{array}{l}\text { Extracellular matrix (dermal } \\
\text { birefringence of mechanically } \\
\text { deformed human skin) }\end{array}$ & 22 \\
\hline Callisto; Thorlabs AG, & Axial resolution of $7 \mu \mathrm{m}$ & Sattler et $\mathrm{al}^{23}$ & Wound healing (after fractional & 20 \\
\hline Lübeck, Germany & $\begin{array}{l}930 \mathrm{~nm} \text { center wavelength, lateral } \\
\text { scan length of } 4 \mathrm{~mm}, 1.7 \mathrm{~mm} \\
\text { penetration depth }\end{array}$ & & $\mathrm{CO}_{2}$ laser treatment) & \\
\hline Santec Inner Vision 2,000; & $50 \mathrm{kHz}$ SS-OCT, axial resolution & Wessels et $\mathrm{al}^{26}$ & Benign and malignant melanocytic & 40 \\
\hline Santec Corporation, & of $\sim 10 \mu \mathrm{m}$, lateral resolution of & & skin lesions & \\
\hline Photonics Valley Ohkusa & $\sim 20 \mu \mathrm{m}$, center wavelength & & & \\
\hline Campus, Komaki, Aichi, Japan & $\mathrm{I}, 300 \pm 60 \mathrm{~nm}$ & & & \\
\hline TD-OCT & $\begin{array}{l}\text { Center wavelength } 1,310 \mathrm{~nm} \text {, } \\
\text { axial resolution of } 10 \mu \mathrm{m}\end{array}$ & Zhao et $\mathrm{al}^{27}$ & Vascular malformations (PWS) & 41 \\
\hline
\end{tabular}

Abbreviations: OCT, optical coherence tomography; SS-OCT, swept-source OCT; NMSC, non-melanoma skin cancer; BCC, basal cell carcinoma; MMS, Mohs micrographic surgery; AA, alopecia areata; ET, epidermal thickness; PDT, photodynamic therapy; $\mathrm{CO}_{2}$, carbon-dioxide; AK, actinic keratosis; HFUS, high-frequency ultrasound; FD-OCT, Fourier Domain OCT; HTC, hydrocortisone; PIM, pimecrolimus; PS-OCT, polarization-sensitive optical coherence tomography; TD-OCT, time domain OCT; PWS, port wine stains; NA, not available; FWHM, full width at half maximum. 


\section{Determination of the epidermal thickness (ET) in healthy skin and cutaneous disorders}

Applying conventional OCT techniques, the epidermis is usually the first clearly distinguishable skin layer, except for the palms and soles. On the aforementioned anatomic sites, the stratum corneum of healthy skin is thick enough (about $300 \mu \mathrm{m}$ ) to be visible at the resolution of conventional scanners. Surprisingly, Tsugita et $\mathrm{a}^{24}$ assessed ET as well as stratum corneum thickness (SCT) in healthy Japanese females ( $\mathrm{n}=116)$ using a conventional OCT scanner (SkinDex300; ISIS Optronics GmbH, Manheim, Germany). The mean \pm SD ET determined at eleven anatomic sites was $68.6 \pm 23.0 \mu \mathrm{m}$ and SCT was $14.1 \pm 1.80 \mu \mathrm{m}$. The authors also found that with increasing age, ET becomes less at some sites but showed no change at other sites, and the comparison between age groups suggested that a thinning trend is generally observed up to the 30 s without continuous changes thereafter. With regard to ET, similar results have previously been reported on Caucasians who were assessed with SkinDex300 as well. ${ }^{1}$ Using the SkinDex300 scanner, Josse et al ${ }^{16}$ assessed 29 healthy subjects and developed a new algorithm for ET determination from cross-sectional OCT images. The algorithm presented by Josse et $\mathrm{al}^{16}$ has shown that a precise automatic measurement of ET can be obtained from OCT images, provided that a consensus on the position of the epidermal/dermal interface can be established. The mean difference between the ET calculated using the algorithm and the ET determined by experts was small, say $<5 \mu \mathrm{m}$ for all the sites assessed, except for the back. This difference was of the same order of magnitude as the inter-observer variations. The comparison of values obtained by the ET algorithm and ET experts revealed a high coefficient of correlation ( $r=0.88$ ); however, more appropriate Bland and Altman plots were not reported. Moreover, because the algorithm accurately locates the dermo-epidermal junction zone in accordance with the experts, it may be concluded that the measurement of ET with this new method is accurate and observer-independent. ${ }^{16}$ We recently aimed to investigate ET in patients with psoriasis $(\mathrm{n}=11)$ and actinic keratoses $(\mathrm{n}=13)$ using routine histology and the high-definition OCT (HDOCT) scanner Skintell (Agfa Healthcare, Mortsel, Belgium; Figure 1) providing a vertical and lateral resolution of $3 \mu \mathrm{m}$ at all depths of the skin sample. ${ }^{12}$ We observed that correct ET determination in strongly hyperkeratotic psoriasis lesions may be impossible using HD-OCT. The penetration depth of the Skintell device is approximately $570 \mu \mathrm{m}$. Hence, conventional OCT, as used by the aforementioned authors, may
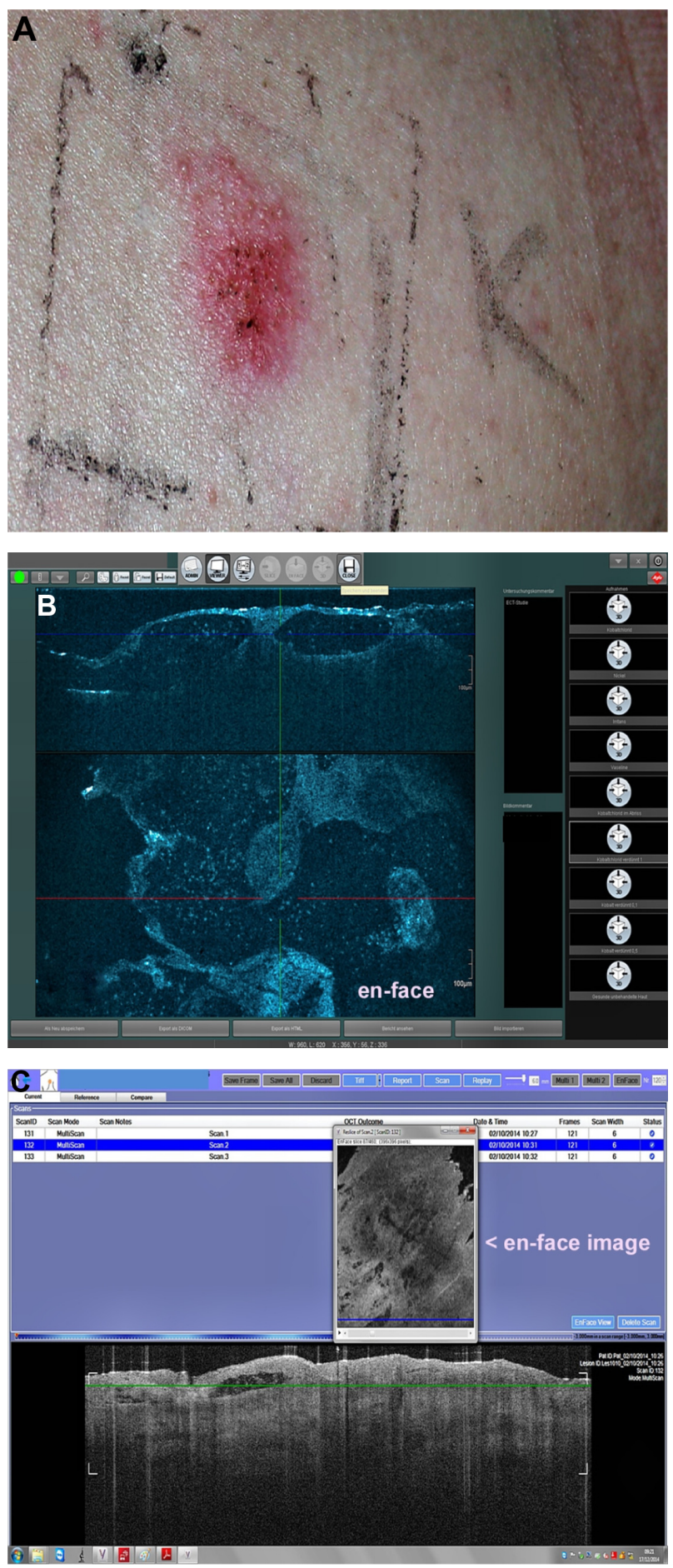

Figure I A positive patch test reaction (A) Skintell (B) VivoSight and (C) OCT images displaying intraepidermal signal-poor cavities that correspond to vesiculation. Abbreviation: OCT, optical coherence tomography.

be more suitable for determining ET of thick hyperkeratotic lesions. By contrast, as shown in Bland and Altman plots, the HD-OCT measurement of ET in relatively thin lesions appears to produce valid results compared with routine histology. Our data indicate that this HD-OCT method for ET determination might be well suited for skin monitoring 
and therapy outcome assessments. In a hyperkeratotic condition, however, the backscattering from the thickened horny layer is higher than that from cellular layers. Therefore, the depth of OCT imaging is reduced in hyperkeratotic conditions such as psoriasis. ${ }^{12}$ A recent study by Morsy et al ${ }^{21}$ suggests that conventional OCT (vertical resolution $8 \mu \mathrm{m}$, lateral resolution $24 \mu \mathrm{m}$ ) resolution may be used to measure ET in psoriasis $(n=23)$ and that these measurements correlate with several other parameters of disease severity. In detail, Morsy et $\mathrm{al}^{21}$ found that compared to normal skin, psoriasis appeared with a more irregular surface and a stronger entrance signal. Moreover, a serrated dermo-epidermal junction and decreased dermal signal intensity were observed. ET measured in untreated psoriasis plaques was thicker, reflecting epidermal hyperproliferation and inflammation. The changes were significantly correlated with the biopsy grading and ET significantly decreased with treatment. ET correlated significantly with self-reported measures of disease severity, but not with physician-determined global psoriasis area and severity score. The data of Morsy et $\mathrm{al}^{21}$ suggest that conventional OCT may be used to measure ET in psoriasis. Notably, the measurements correlated with several other parameters of disease severity indicating that the OCT assessment of psoriatic plaques may provide a useful method for noninvasive in vivo imaging to follow the evolution of psoriasis lesions. ${ }^{21}$ Aschoff et $\mathrm{al}^{5}$ reported on an 8-week, investigator-blinded, intraindividual right-left comparison study of patients with atopic dermatitis. In this trial, hydrocortisone (HCT) 1\% cream was applied twice daily for 4 weeks on one side of a non-lesional forehead skin, and pimecrolimus (PIM) 1\% cream on the other. ET investigated by conventional OCT treatment with HCT led to a significant decrease in ET after only 2 weeks of treatment, while the slight decrease in PIM-treated sites was not statistically significant. Four weeks post-treatment, ET returned to baseline values. Using the conventional OCT technique, Aschoff et $\mathrm{al}^{5}$ demonstrated that a 2-week single course of topical treatment with a mildly potent steroid can cause transient epidermal thinning, an effect not seen in the PIM group. This study suggests that PIM may be safer for treatment of atopic dermatitis in sensitive skin areas like the face, especially when repeated application is required. ${ }^{5}$

\section{Skin appendages}

The usefulness of OCT has already been established for the investigation of skin appendages such as hairs and nails. Similar to histology, OCT provides highly reproducible measurements of hair shaft thickness, including hair shaft diameter, cross-sectional surface area, and hair shape. Hence, OCT technique is a promising method that provides better insight into the pathogenesis of different diseases affecting hairs and different structural hair changes in vivo. Using the OCT system SkinDex300, Garcia Bartels et al ${ }^{13}$ investigated patients suffering from alopecia areata (AA). Fifty hairs from the border of an AA lesion and 50 hairs of an unaffected area were examined by OCT. In all cases, the cross-section (CS) of the hairs inside of the skin area affected by AA was significantly lower compared with unaffected scalp areas. The authors presume that changes in metabolism or perifollicular inflammation influence the hair structure directly. Moreover, OCT measurements have the advantage that hairs need not be cut and still grow after measurement. Thus, kinetic studies regarding the changes in hair parameters could be carried out. ${ }^{13}$ Another study by Lindner et al ${ }^{17}$ evaluated by means of the same OCT system SkinDex300 the hair-shaft alterations after chemotherapy and tamoxifen therapy in patients with breast cancer ( $n=34 ; 17$ receiving tamoxifen and 17 chemotherapy). The investigated hair parameters were characterized by $\mathrm{CS}$ and form factor (FF), which was determined by the ratio of maximal to minimal hair diameters. The authors found out that changes were observed neither in CS nor in FF in patients treated with tamoxifen. By contrast, in patients who have received chemotherapy, significantly lower CS and FF were observed after treatment. This study found a morphological correlation to the reported changes of hair structure. As OCT measurements revealed, regrowing hair after cancer chemotherapy shows a decreased $\mathrm{CS}$ and an altered FF. ${ }^{17}$

The accuracy of OCT for measuring nail thickness has previously been reported. ${ }^{29}$ Most of the studies addressed fungal nail infections and characteristic OCT morphologic patterns. A recent study of Aydin et $\mathrm{al}^{6}$ examined the potential use of the VivoSight OCT probe (Michelson Diagnostics, Kent, UK; Figure 1) for the assessment of nail disease in psoriasis and psoriasis arthritis. Currently, the clinical nail psoriasis severity index is still the gold standard. The authors suggested that OCT has the potential to become the modality of choice for imaging the nail in subjects with psoriasis nail disease. This technique could permit a more objective imaging assessment of nail disease, and may be helpful in the diagnosis and monitoring of treatment response. In this study, among 180 investigated nails, OCT had a sensitivity and specificity of $44.4 \%$ and $95.8 \%$, respectively. Further studies have to be performed to gain more reliable data, particularly with regard to standardization of the nail assessment. ${ }^{6}$ 


\section{Wound healing}

Recently, Greaves et al ${ }^{14}$ compared OCT to histological assessment of acute wound healing by means of the VivoSight OCT scanner. Characteristically architectural changes that correlate with histological phases of cutaneous wound healing could be identified with OCT. Therefore, $5 \mathrm{~mm}$ punch biopsies were harvested from 50 healthy volunteers and these wounds were assessed weekly for a 6-week period by OCT in comparison to histological findings. As an assessment tool, the mean grayscale value (MGV) of the upper reticular dermis was derived from OCT images at all time points. It could be found that both techniques showed anatomical congruity in normal and wounded skin with correlating architectural changes associated with inflammatory, proliferative, and remodeling wound healing phases. MGV was significantly increased 6 weeks after wounding. Thus, the authors presume OCT-derived MGVs as a novel measure of wound fibrosis on which further studies are required to prove the efficacy and accuracy.${ }^{14}$ Another study group evaluated the kinetics and quantification of wound healing after fractional laser therapy. Sattler et $\mathrm{al}^{23}$ treated 20 healthy volunteers with fractional carbon-dioxide $\left(\mathrm{CO}_{2}\right)$ laser with $8 \mathrm{~W}$ and $16 \mathrm{~W}$ laser power, respectively. Optical measurements were performed at six time points over a 21-day observation period using the frequency-domain OCT system Callisto (Thorlabs AG, Lübeck, Germany) with an axial resolution of $7 \mu \mathrm{m}$ (930 $\mathrm{nm}$ center wavelength, lateral scan length of $4 \mathrm{~mm}$, and $1.7 \mathrm{~mm}$ penetration depth). The authors reported that the correlation of the specific characteristics by OCT with the findings known from histopathological studies has been excellent. It was possible to visualize and quantify the kinetics of wound healing processes and the therapeutic effects in the upper layers of the skin in real-time. Although wound healing seemed to be completed after day 7-14 clinically, on day 21 in $89.5 \%$ of the $8 \mathrm{~W}$-treated areas and $100 \%$ in the $16 \mathrm{~W}$-treated areas, subepidermal skin damages have been still visible. ${ }^{23}$

\section{Extracellular matrix and skin fibrosis}

Sakai et $\mathrm{al}^{22}$ carried out an in vivo three-dimensional analysis of anisotropic changes in the dermal birefringence of mechanically deformed human skin of 22 males using polarization-sensitive optical coherence tomography (PS-OCT). They observed that the papillary-dermal birefringence of the forehead increased significantly when the skin was shrunk parallel to the body axis; by contrast, when the skin was shrunk perpendicular to the body axis, it decreased significantly. En-face images of the papillarydermal birefringence showed variations among individual subjects. Sakai et a ${ }^{22}$ also found that both shrinking parallel to and stretching in perpendicular to the body axis promoted the formation of macro rope-like birefringent domains. Sakai et $\mathrm{al}^{22}$ found that the papillary-dermal birefringence of the forehead skin has an anisotropic property, and concluded that PS-OCT is useful for understanding the in vivo anisotropic properties of the collagen structure and inner stress in the skin. PS-OCT might therefore be a promising diagnostic tool in cosmetics and fibrosis research. ${ }^{22}$

Abignano et al ${ }^{4}$ recently reported on OCT measurements in 22 patients with scleroderma and 22 healthy controls. The OCT scans were performed using the VivoSight topical OCT. They found that a comparison of OCT images with skin histology revealed a progressive loss of demarcation of the dermo-epidermal junction zone associated with dermal fibrosis. Scleroderma-affected skin showed a significant decrease of optical density in the papillary dermis, particularly pronounced in patients with worse modified Rodnan skin score. Abignano et $\mathrm{al}^{4}$ also observed that unaffected skin was distinguishable from healthy skin by its specific pattern of optical density decrease in the reticular dermis. The authors evaluated OCT skin imaging as a reliable and quantitative tool that could be used as a surrogate marker of skin fibrosis. The technique used required minimal operator training and application time ( $<10$ seconds per site), offering the great advantage of saving image files for further or centralized operator-independent analysis. Despite these promising data, longitudinal studies including a larger number of patients with different degrees of fibrosis and assessing the sensitivity to change over time and over treatment are needed to validate OCT methods as a quantitative outcome measure in scleroderma. ${ }^{4}$ In this regard, conventional or PSOCT techniques are likely superior to HD-OCT as the latter is more limited in scanning depth.

\section{Vascular malformations}

Vascular malformations commonly occur in the facial region, and can be associated with significant stigma and embarrassment. Therefore, patients are seeking effective treatment. Regrettably, even the recommended light-based treatment options do not always lead to a complete clearance. OCT represents a suitable method to investigate both anatomical structures of vascular malformations and treatment outcomes. Zhao et $\mathrm{a}^{27}$ investigated in 41 Chinese patients port wine stains (PWS) on the face and neck using a portable time-domain OCT system (center wavelength of 1,310 nm) 
with an axial resolution of $10 \mu \mathrm{m}$. They studied the correlation between morphological findings and photodynamic therapy (PDT) outcomes. The structural parameters, including the ET, diameter, and depth of dilated blood vessels, were obtained. PDT was performed with laser as the light source, and an intensity of $100 \mathrm{~mW} / \mathrm{cm}^{2}$ in adults and $60 \mathrm{~mW} / \mathrm{cm}^{2}$ in children. It was found that the depth of blood vessels obtained from OCT images may be beneficial to study the relationship between therapeutic effects and therapeutic times. ${ }^{27}$ Given the fact that current treatment settings are mainly chosen on the basis of PWS's color, OCT technique appear to provide more measurable objective criteria. ${ }^{27}$

\section{Nonmelanoma skin cancer (NMSC)}

The term NMSC predominantly comprises common skin tumors such as basal cell carcinoma (BCC), squamous cell carcinoma (SCC), and actinic keratosis (AK). In daily dermatological practice, the investigation of NMSC plays a crucial role beside other indications. We analyzed the data of 1,000 OCT scans performed by means of the VivoSight scanner at six German institutions, and found that $82.9 \%$ of performed scans have been related to NMSC. ${ }^{30}$ Characteristic OCT imaging features have been described in various studies for NMSC lesions (Figure 2). Some examples are disruption of layering (AK, BCC), thickening of epidermis (AK), white streaks and dots in the epidermis (hyperkeratotic AK), and dark rounded areas known as palisading of tumor cells (BCC). Mogensen et $\mathrm{al}^{19}$ assessed the diagnostic accuracy of OCT in differentiating NMSC from benign lesions and normal skin using an OCT system developed at the Technical University of Denmark (1,318 nm center wavelength, axial and lateral resolution of $8 \mu \mathrm{m}$ and $24 \mu \mathrm{m}$, respectively), which generates PS-OCT images parallel with standard OCT images. The authors performed an observer-blinded evaluation by dermatologists and a pathologist in 104 patients with 176 lesions (64 BCC, 1 SCC, 39 AK, 2 malignant melanoma, 9 benign lesions, 105 scans of adjacent skin) scanned by OCT. The authors reported a sensitivity of $79 \%-94 \%$, and a
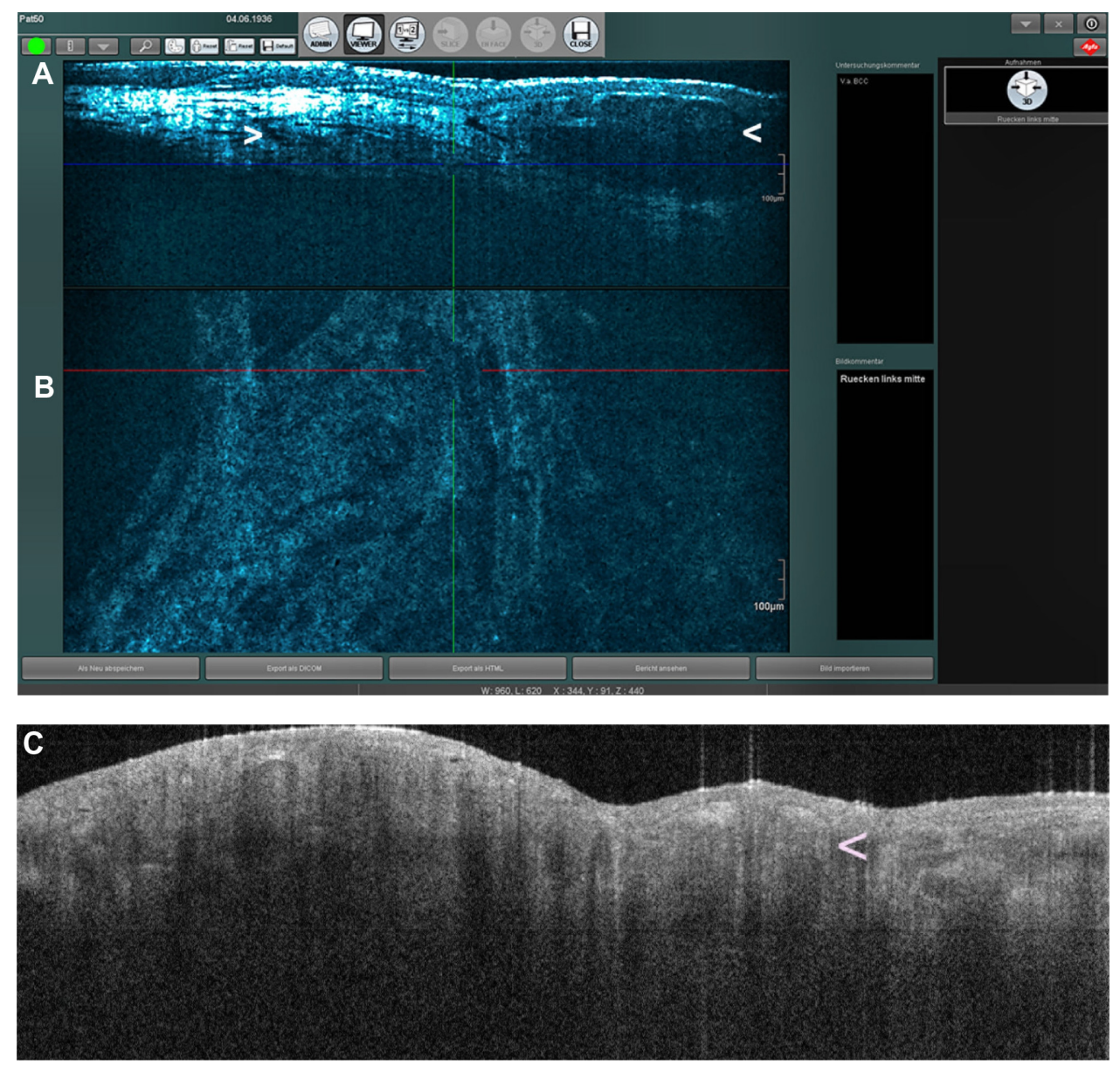

Figure 2 OCT images of a superficial BCC.

Notes: Tumor nodules (arrow heads) are detectable using the Skintell (slice mode [A]; en-face mode [B]) as well as VivoSight (C) scanners.

Abbreviations: OCT, optical coherence tomography; BCC, basal cell carcinoma. 
specificity of $85 \%-96 \%$ in differentiating normal skin from lesions. Discrimination of BCC from AK had an error rate of $50 \%-52 \% .{ }^{19}$ According to analogous findings obtained by Korde et al, ${ }^{31} \mathrm{AK}$ can be distinguished from nondiseased skin with $86 \%$ sensitivity and $83 \%$ specificity. Nevertheless, the optical evaluation of AK lesions is often limited, in particular according to surface hyperkeratosis, which causes "shadowing" effects in depth.

Scola et $\mathrm{al}^{28}$ compared PDT and $\mathrm{CO}_{2}$ laser ablation in the management of multiple actinic keratoses using, among others, OCT. Using the SkinDex300 scanner, Scola et $\mathrm{al}^{28}$ investigated patients $(n=20)$ with at least four bilateral lesions before and 4 weeks after treatment. They evaluated ET as well as characteristic white streaks as a correlate for hyperkeratosis. Scola et $\mathrm{al}^{28}$ showed a significant reduction of ET after both treatments. The quantity of white streaks was also significantly reduced after both approaches. ET as well as white streaks showed a tendency toward a greater reduction after PDT, but statistical significance was not shown. ${ }^{28}$

HD-OCT scanners have recently been developed, providing a significantly higher resolution than conventional OCT. Most of these systems are capable of capturing slice images and en-face images in real-time, as well as threedimensional acquisition. Using HD-OCT, Maier et $\mathrm{al}^{32}$ described in the en-face mode lobulated nodules, peripheral rimming, epidermal disarray, dilated vessels, and variably refractile stroma, and in slice mode gray/dark oval structures, peripheral rimming, destruction of layering, and dilated vessels, as well as peritumoral bright stroma. Using the Skintell scanner device, we recently assessed 25 histopathologically confirmed BCC lesions, and searched for predictors for the most common tumor subtypes. ${ }^{9}$ Using HD-OCT, it was not possible to differentiate between superficial and solid BCC subtypes. However, we have shown for the first time that peripheral rimming in HD-OCT correlates with peritumoral mucin deposition. ${ }^{9}$

An accurate assessment of tumor size is important when planning treatment of NMSC. It has to be differentiated between vertical tumor invasion depth and delineating lateral tumor borders. Tumor thickness is an important aspect for conservative as well as surgical treatment options, whereas lateral tumor expansion mainly affects surgical therapies. Penetration depth may be determined to a thickness of about $1.5 \mathrm{~mm}$ by conventional OCT scanners. The invasion depth may be overestimated when there is an accompanying inflammatory infiltrate, for example. ${ }^{30}$ According to another study by Mogensen et $\mathrm{al}^{20}$ comparing in vivo thickness measurement of BCC and $\mathrm{AK}$ with OCT and $20 \mathrm{MHz}$ high-frequency ultra- sound (HFUS) OCT appears more precise and less biased than HFUS. OCT, and particularly HFUS, tended to overestimate tumor thickness in NMSC lesions $<2 \mathrm{~mm}$ of depth. ${ }^{20}$

Wang et $\mathrm{a}^{25}$ investigated the feasibility and diagnostic value of using in vivo OCT to define excision margins before Mohs micrographic surgery (MMS) of BCC $(n=52)$. Therefore, excision margins were compared with those of OCT-assessed borders, and validated with histologic assessments. In lesions requiring more than one MMS stage, OCT always indicated that the lesion boundary would extend outside the planned MMS defect boundary. This study showed the prospective utility of OCT to refine clinically estimated borders for MMS, and may reduce the excised area. ${ }^{25}$ Further studies have to be conducted to confirm the given hints. Mogensen et $\mathrm{al}^{20}$ concluded that OCT diagnosis is less accurate than clinical diagnosis. However, high accuracy in distinguishing lesions from normal skin, crucial for delineating tumor borders, was obtained. ${ }^{20}$ According to Cunha et al, ${ }^{8}$ another approach may be ex vivo OCT by means of the VivoSight scanner. They compared the efficiency and accuracy of ex vivo OCT with frozen-section histology for identifying $\mathrm{BCC}(\mathrm{n}=75)$ in MMS. The sensitivity and specificity were $19 \%$ and $56 \%$, respectively. Although it was possible to identify BCC with ex vivo OCT, tumor visualization is poor, and currently, does not add any practical benefits. ${ }^{8}$

\section{Malignant melanoma}

Previous studies on conventional OCT revealed that images of melanocytic nevi frequently show an accentuated epidermal layer and elongated rete ridges. Nests of nevus cells can be recognized as signal poor areas with a typical pattern in the apical part of the rete ridges. Strongly pigmented lesions, which show a stronger scattering of light, have more uniform signal intensity than healthy skin. In infiltrative growing melanoma or deep compound nevi, the second intensity peak, which represents the border between the epidermis and dermis, may disappear. ${ }^{1-3}$ Hinz et al $^{15}$ investigated 26 melanocytic skin lesions by means of histopathology, conventional swept-source $(1,325 \mathrm{~nm}$ center wavelength, $25 \mu \mathrm{m}$ [lateral] $\times$ $12 \mu \mathrm{m}$ [axial] resolution [air], and maximum theoretical imaging depth of $3 \mathrm{~mm}$ [air]) OCT (SS-OCT) (OCS1300SS; Thorlabs $^{\circledR}$, Dachau, Germany), and $20 \mathrm{MHz}$ HFUS. Vertical tumor thickness measurements of both methods were compared with histopathological assessments. With respect to the "gold standard" (histopathology), OCT revealed more exact vertical tumor thickness measurements of melanocytic lesions, compared to HFUS. Hinz et $\mathrm{al}^{15}$ observed a considerably higher median difference $(0.16 \mathrm{~mm})$ between HFUS 
and histopathology tumor thickness measurements, compared to the assessments by OCT and histopathology $(0.08 \mathrm{~mm})$. Compared to histopathology, both imaging methods tended toward overestimation. Hinz et $\mathrm{al}^{15}$ concluded that OCT might be a suitable tool for noninvasive tumor thickness measurement in melanocytic skin lesions, and is superior to HFUS in the treatment of thin melanocytic tumors $(<1 \mathrm{~mm})$. Using histopathology, $25 \mathrm{MHz}$ HFUS and spectral domain (930 nm center wavelength, lateral resolution $8 \mu \mathrm{m}$ ), and OCT (Thorlabs ${ }^{\circledR}$, Newton, NJ, USA) Meyer et al ${ }^{18}$ investigated the tumor thickness of 138 melanocytic skin lesions. They found that HFUS showed a good level of agreement with histology, and excellent inter-rater reproducibility, resulting in reliable in vivo assessment of tumor thickness. OCT revealed a poor level of agreement with histopathology, and the inter-rater reproducibility was zero. The discrepancies of the two aforementioned papers can be at least in part explained by the different technologies used, eg, the OCT scanners significantly differed with regard to lateral resolution and penetration depth. Moreover, the study of Meyer et al included more lesions with tumor thickness greater than $1 \mathrm{~mm} .{ }^{18}$ Wessels et al ${ }^{26}$ investigated benign $(\mathrm{n}=33)$ and malignant $(\mathrm{n}=7)$ melanocytic skin lesions using an SS-OCT system (Santec Inner Vision 2,000; Santec Corporation, Photonics Valley Ohkusa Campus, Komaki, Aichi, Japan). The mean attenuation coefficient of benign lesions was $5.49 \mathrm{~mm}^{-1}$. By contrast, the mean attenuation coefficient of melanomas was $4.28 \mathrm{~mm}^{-1}$, and thus significantly different from the attenuation coefficient observed in nevi $(P=0.02)$. The diagnostic accuracy of the attenuation coefficient determination was moderate with a sensitivity of $77 \%$ (95\% confidence interval $57 \%-96 \%$ ).

Using the slice and en-face mode of HD-OCT (Skintell), and corresponding vertical and horizontal histopathology, we recently showed that it is possible to visualize architectural as well as cellular alterations of melanocytic skin lesions $(n=48) .{ }^{10}$ We showed that pagetoid cells, fusion of rete ridges, and junctional and/or dermal nests with atypical cells are significantly more frequently seen in melanoma when compared to benign nevi. Due to its higher resolution, HD-OCT appears to have a considerably higher diagnostic potential in differentiating between benign and malignant melanocytic skin lesions when compared to conventional OCT. However, we also observed a substantial overlap of HD-OCT features seen in melanocytic skin lesions, and the absence of suspicious HD-OCT features in some thin melanomas represents an important limitation of HD-OCT affecting the sensitivity of the method. ${ }^{10}$ In order to find out more on the diagnostic accuracy of HD-OCT (Skintell) in the differentiation between benign and malignant melanocytic skin lesions, we performed a multicenter observer-blinded study investigating 66 nevi and 27 melanomas. ${ }^{11}$ The sensitivity of HD-OCT was $74.1 \%$ (95\% confidence interval $53.7 \%-88.8 \%)$, whereas the specificity was $92.4 \%(95 \%$ confidence interval $83.2 \%-97.5 \%$ ). The positive predictive value was $80 \%$ (95\% confidence interval 59.3\%-93.1\%), and the negative predictive value $89.7 \%$ (95\% confidence interval $79.9 \%-95.7 \%$ ). Hence, in the differentiation of benign and malignant melanocytic skin lesions, HD-OCT appears to have a moderate diagnostic potential that is inferior to other competing techniques such as reflectance confocal microscopy in vivo. ${ }^{11}$

\section{Comment and outlook}

Using OCT, it is possible to characterize normal and pathologic skin morphology by providing high-resolution images similar to the tissue architecture observed in routine histology. OCT imaging represents a nontraumatic and time-efficient approach to the diagnosis and monitoring of a number of skin conditions, while ensuring patient comfort. The images obtained by OCT may help in elucidating correlations between histopathology for integrated evaluation in research. Advances in OCT technology and further research on clinical applications have the potential to contribute to the trend toward nonsurgical evaluation. During the last 5 years, a variety of research data has been published on OCT and the skin. In particular, we recently gained more insight into the utility of OCT in the evaluation of melanocytic skin lesions, skin fibrosis, and NMSC. ${ }^{33-35}$ Combining OCT with other imaging techniques, such as Raman, Doppler, fluorescence, and ultrasound, may further improve the diagnostic performance of OCT in skin research as well as future dermatology practice. ${ }^{36-39}$ However, more systematic clinical studies on reasonable sample sizes are required to validate the applications of OCT in dermatology. These studies will be challenging because of stringent statistical performance criteria, such as sensitivity and specificity.

\section{Disclosure}

The authors report no conflicts of interest in this work.

\section{References}

1. Gambichler T, Jaedicke V, Terras S. Optical coherence tomography in dermatology: technical and clinical aspects. Arch Dermatol Res. 2011;303(7):457-473.

2. Mogensen M, Thrane L, Joergensen TM, Andersen PE, Jemec GB. Optical coherence tomography for imaging of skin and skin diseases. Semin Cutan Med Surg. 2009;28(3):196-202. 
3. Welzel J. Optische Kohärenztomographie [Optical coherence tomography]. Hautarzt. 2010;61(5): 416-420. German.

4. Abignano G, Aydin SZ, Castillo-Gallego C, et al. Virtual skin biopsy by optical coherence tomography: the first quantitative imaging biomarker for scleroderma. Ann Rheum Dis. 2013;72(11):1845-1851.

5. Aschoff R, Schmitt J, Knuschke P, Koch E, Brautigam M, Meurer M. Evaluation of the atrophogenic potential of hydrocortisone $1 \%$ cream and pimecrolimus $1 \%$ cream in uninvolved forehead skin of patients with atopic dermatitis using optical coherence tomography. Exp Dermatol. 2011;20(10):832-836.

6. Aydin SZ, Castillo-Gallego C, Ash ZR, et al. Potential use of optical coherence tomography and high-frequency ultrasound for the assessment of nail disease in psoriasis and psoriatic arthritis. Dermatology. 2013;227(1):45-51.

7. Coleman AJ, Richardson TJ, Orchard G, Uddin A, Choi MJ, Lacy KE. Histological correlates of optical coherence tomography in non-melanoma skin cancer. Skin Res Technol. 2013;19(1):10-19.

8. Cunha D, Richardson T, Sheth N, Orchard G, Coleman A, Mallipeddi R. Comparison of ex vivo optical coherence tomography with conventional frozen-section histology for visualizing basal cell carcinoma during Mohs micrographic surgery. Br J Dermatol. 2011;165(3):576-580.

9. Gambichler T, Plura I, Kampilafkos P, et al. Histopathological correlates of basal cell carcinoma in the slice and en face imaging modes of high-definition optical coherence tomography. Br J Dermatol. 2014;170(6):1358-1361.

10. Gambichler T, Plura I, Schmid-Wendtner M, et al. High-definition optical coherence tomography of melanocytic skin lesions. J Biophotonics. 2014;9999(9999).

11. Gambichler T, Schmid-Wendtner MH, Plura I, et al. A multicentre pilot study investigating high-definition optical coherence tomography in the differentiation of cutaneous melanoma and melanocytic naevi. $J$ Eur Acad Dermatol Venereol. 2014;29(3):537-541.

12. Gambichler T, Valavanis K, Plura I, Georgas D, Kampilafkos P, Stucker M. In vivo determination of epidermal thickness using highdefinition optical coherence tomography. Br J Dermatol. 2014;170(3): 737-739.

13. Garcia Bartels N, Jahnke I, Patzelt A, Richter H, Lademann J, BlumePeytavi U. Hair shaft abnormalities in alopecia areata evaluated by optical coherence tomography. Skin Res Technol. 2011;17(2):201-205.

14. Greaves NS, Benatar B, Whiteside S, Alonso-Rasgado T, Baguneid M, Bayat A. Optical coherence tomography: a reliable alternative to invasive histological assessment of acute wound healing in human skin? Br J Dermatol. 2014;170(4):840-850.

15. Hinz T, Ehler LK, Voth H, et al. Assessment of tumor thickness in melanocytic skin lesions: comparison of optical coherence tomography, 20-MHz ultrasound and histopathology. Dermatology. 2011;223(2):161-168.

16. Josse G, George J, Black D. Automatic measurement of epidermal thickness from optical coherence tomography images using a new algorithm. Skin Res Technol. 2011;17(3):314-319.

17. Lindner J, Hillmann K, Blume-Peytavi U, et al. Hair shaft abnormalities after chemotherapy and tamoxifen therapy in patients with breast cancer evaluated by optical coherence tomography. $\mathrm{Br} J$ Dermatol. 2012;167(6):1272-1278.

18. Meyer N, Lauwers-Cances V, Lourari S, et al. High-frequency ultrasonography but not $930-\mathrm{nm}$ optical coherence tomography reliably evaluates melanoma thickness in vivo: a prospective validation study. Br J Dermatol. 2014;171(4):799-805.

19. Mogensen M, Joergensen TM, Nürnberg BM, et al. Assessment of optical coherence tomography imaging in the diagnosis of non-melanoma skin cancer and benign lesions versus normal skin: observer-blinded evaluation by dermatologists and pathologists. Dermatol Surg. 2009;35(6):965-972.

20. Mogensen M, Nurnberg BM, Forman JL, Thomsen JB, Thrane L, Jemec GB. In vivo thickness measurement of basal cell carcinoma and actinic keratosis with optical coherence tomography and $20 \mathrm{MHz}$ ultrasound. Br J Dermatol. 2009;160(5):1026-1033.
21. Morsy H, Kamp S, Thrane L, et al. Optical coherence tomography imaging of psoriasis vulgaris: correlation with histology and disease severity. Arch Dermatol Res. 2010;302(2):105-111.

22. Sakai S, Yamanari M, Lim Y, Nakagawa N, Yasuno Y. In vivo evaluation of human skin anisotropy by polarization-sensitive optical coherence tomography. Biomed Opt Express. 2011;2(9):2623-2631.

23. Sattler EC, Poloczek K, Kastle R, Welzel J. Confocal laser scanning microscopy and optical coherence tomography for the evaluation of the kinetics and quantification of wound healing after fractional laser therapy. J Am Acad Dermatol. 2013;69(4):e165-e173.

24. Tsugita T, Nishijima T, Kitahara T, Takema Y. Positional differences and aging changes in Japanese woman epidermal thickness and corneous thickness determined by OCT (optical coherence tomography). Skin Res Technol. 2013;19(3):242-250.

25. Wang KX, Meekings A, Fluhr JW, et al. Optical coherence tomographybased optimization of mohs micrographic surgery of Basal cell carcinoma: a pilot study. Dermatol Surg. 2013;39(4):627-633.

26. Wessels R, de Bruin DM, Relyveld GN, et al. Functional optical coherence tomography of pigmented lesions. J Eur Acad Dermatol Venereol. Epub 2014 Aug 29.

27. Zhao S, Gu Y, Xue P, et al. Imaging port wine stains by fiber optical coherence tomography. J Biomed Opt. 2010;15(3):036020.

28. Scola N, Terras S, Georgas D, et al. A randomized, half-side comparative study of aminolaevulinate photodynamic therapy vs $\mathrm{CO}(2)$ laser ablation in immunocompetent patients with multiple actinic keratoses. Br J Dermatol. 2012;167(6):1366-1373.

29. Ash ZR, Tinazzi I, Gallego CC, et al. Psoriasis patients with nail disease have a greater magnitude of underlying systemic subclinical enthesopathy than those with normal nails. Ann Rheum Dis. 2012;71(4): $553-556$.

30. Schmitz L, Reinhold U, Bierhoff E, Dirschka T. Optical coherence tomography: its role in daily dermatological practice. J Dtsch Dermatol Ges. 2013;11(6):499-507.

31. Korde VR, Bonnema GT, Xu W, et al. Using optical coherence tomography to evaluate skin sun damage and precancer. Lasers Surg Med. 2007;39(9):687-695.

32. Maier T, Braun-Falco M, Hinz T, Schmid-Wendtner MH, Ruzicka T, Berking C. Morphology of basal cell carcinoma in high definition optical coherence tomography: en-face and slice imaging mode, and comparison with histology. J Eur Acad Dermatol Venereol. 2013; 27(1):e97-e104.

33. Boone M, Norrenberg S, Jemec G, Del Marmol V. High-definition optical coherence tomography: adapted algorithmic method for pattern analysis of inflammatory skin diseases: a pilot study. Arch Dermatol Res. 2013;305(4):283-297.

34. Boone MA, Norrenberg S, Jemec GB, Del Marmol V. Imaging of basal cell carcinoma by high-definition optical coherence tomography: histomorphological correlation. A pilot study. Br J Dermatol. 2012; 167(4):856-864.

35. Boone MA, Norrenberg S, Jemec GB, Del Marmol V. High-definition optical coherence tomography imaging of melanocytic lesions: a pilot study. Arch Dermatol Res. 2014;306(1):11-26.

36. Dalimier E, Salomon D. Full-field optical coherence tomography: a new technology for 3D high-resolution skin imaging. Dermatology. 2012;224(1):84-92.

37. Durkin JR, Fine JL, Sam H, Pugliano-Mauro M, Ho J. Imaging of Mohs micrographic surgery sections using full-field optical coherence tomography: a pilot study. Dermatol Surg. 2014;40(3):266-274.

38. Hussain AA, Themstrup L, Jemec GB. Optical coherence tomography in the diagnosis of basal cell carcinoma. Arch Dermatol Res. 2015;307(1):1-10

39. Lee KS, Zhao H, Ibrahim SF, Meemon N, Khoudeir L, Rolland JP. Three-dimensional imaging of normal skin and nonmelanoma skin cancer with cellular resolution using Gabor domain optical coherence microscopy. J Biomed Opt. 2012;17(12):126006. 


\section{Publish your work in this journal}

Clinical, Cosmetic and Investigational Dermatology is an international, peer-reviewed, open access, online journal that focuses on the latest clinical and experimental research in all aspects of skin disease and cosmetic interventions. All areas of dermatology will be covered; contributions will be welcomed from all clinicians and

basic science researchers globally. This journal is indexed on CAS.

The manuscript management system is completely online and includes

a very quick and fair peer-review system, which is all easy to use. Visit http://www.dovepress.com/testimonials.php to read real quotes from published authors.

Submit your manuscript here: http://www.dovepress.com/clinical-cosmetic-and-investigational-dermatology-journal 